\title{
LA VIOLENCIA Y COHESIÓN SOCIAL, UNA APROXIMACIÓN A LA CONSTRUCCIÓN DE UN ÍNDICE DE COHESIÓN SOCIAL. ESTUDIO DE CASO COMUNA 11 DE DOSQUEBRADAS, AÑO 2013.
}

\section{VIOLENCE AND SOCIAL COHESION, AN APPROACH TO THE CONSTRUCTION OF AN INDEX OF SOCIAL COHESION. CASE STUDY COMMUNE DOSQUEBRADAS 11, 2013.}

\section{Williams Gilberto Jiménez García ${ }^{1}$}

\section{Resumen}

El presente artículo muestra los resultados de un estudio de caso, el cual tiene como objetivo reflexionar sobre la relación que tiene la violencia y la cohesión social en un territorio especifico. Esta es una investigación fenomenológica y tiene como enfoque metodológico una combinación cuali-cuantitativa. En este estudio se comprobó que existe significancia estadística entre las variables abordadas, permitiendo concluir que hay relación entre la violencia y el nivel de cohesión social. Para comprobar esta relación se construyó también un indicador de cohesión social a partir de una encuesta y la adaptación de varias encuestas de cohesión social.

Palabras claves: violencia, violencia estructural, factores sociales, cohesión social

\begin{abstract}
This paper presents the results of a case study, which aims to reflect on the relationship of the violence and social cohesion in a specific territory. This is a phenomenological research and its methodological approach a combination between quantitative and qualitative methods. This study found that there is statistical significance between the variables addressed, to the conclusion that there is a relationship between violence and the level of social cohesion. To test this relationship is also built an indicator of social cohesion from a survey and the adaptation of several surveys of social cohesion.
\end{abstract}

Keywords: violence, structural violence, social factors, social cohesion

\footnotetext{
${ }^{1}$ Estudiante de doctorado en Ciencias Humanas y Sociales, Universidad Nacional de Colombia. Msc en Hábitat, Universidad Nacional de Colombia. Administrador Ambiental, Universidad Tecnológica de Pereira. E-mail:wgjimanezg@unal.edu.co
} 


\section{A MANERA DE INTRODUCCIÓN}

El presente artículo es un estudio de caso que tiene como objetivo reflexionar sobre la relación que tiene la violencia con la cohesión social en los barrios, a partir del uso de un enfoque metodológico que combina lo cualitativo y lo cuantitativo. En este sentido, se plantea la siguiente pregunta de investigación: "existe alguna relación entre la cohesión social de los habitantes de una comuna y la violencia de tipo socio-económico que se presenta en los barrios, medida principalmente por hurtos, homicidios y percepción de violencia"

En este sentido, en primera instancia se ofrece una relación conceptual entre la violencia y la cohesión social, encontrando que son diferentes los elementos aglutinadores de cada sociedad (así todos provengan del gran marco civilizatorio auto-referenciado como es occidente). A continuación, se intenta aportar a la discusión académica la construcción de un índice de cohesión social, el cuál es diseñado y aplicado para el presente caso de estudio, y que pretende medir cuanti-cualitativamente el estado de la cohesión social en un hábitat determinado (ciudad, comuna o barrio).

Posteriormente, se realiza una discusión de los resultados y se emplea una prueba de significación estadística para confirmar si existe una relación entre las variables de cohesión social y la experiencia de victimización de los habitantes de la comuna 11 de Dosquebradas, lo que finalmente permitió construir las conclusiones pertinentes para el presente estudio.

\section{COHESIÓN SOCIAL Y VIOLENCIA, RELACIONES CONCEPTUALES}

Los cuestionamientos sobre qué mantiene unida a la sociedad y las condiciones que deben crear en el contexto político y económico las instituciones de la sociedad para generar identidad y articulación entre los diferentes actores sociales, son la preocupación central de las organizaciones que procuran por el entendimiento del colectivo en un contexto social y económico.

En América Latina y el Caribe, la cohesión social ha emergido camuflada en la necesidad de encarar las problemáticas de extrema desigualdad y pobreza que se presentan en esta región, así como las diversas formas de discriminación y exclusión social que se acentúan en estas sociedades. En este sentido, Feres en CEPAL (2007) define a la cohesión social como la dialéctica entre (1) los mecanismos instituidos de inclusión/exclusión social y (2) las respuestas de la ciudadanía, frente al modo en que dichos mecanismos operan, esto directamente relacionado con el sentido de pertenencia. 
La cohesión social es un fenómeno que no permite una definición univoca, sin embargo precisa de una delimitación para que no se vuelva etéreo. En algunos contextos se le relaciona con los lazos sociales, la gobernabilidad de los Estados, la equidad, la inclusión social, la identidad social, la racionalización económica, la solidaridad, el bienestar y la concepción de lo público.

En el contexto de las ciencias sociales, la $\operatorname{CEPAL}(2007,16)$ define a la cohesión social como:

[...] el efecto combinado del nivel de brechas de bienestar entre individuos y entre grupos, los mecanismos que integran a los individuos y grupos a la dinámica social y el sentido de adhesión y pertenencia a la sociedad por parte de ellos". [Así mismo, se puede decir que es el grado de consenso de una comunidad] (...) sobre la percepción de pertenencia a un proyecto o situación en común".

La contribución de Durkheim (1987) al concepto de cohesión social es fundamental, en cuanto introduce los términos de solidaridad, pertenencia e integración social, los cuales son necesarios para que los miembros de una sociedad sigan vinculados a ella con una fuerza superior a las realidades económicas y políticas que presionan nuevos (des)ordenes sociales. Para ello Durkheim propuso que estos lazos se debían multiplicar, fortalecer y generar sentimientos e ideas que unan a los miembros de la sociedad. Lazos que crean obligaciones al individuo que permiten reprimir el egoísmo y reconocer su correspondencia con la sociedad.

Desde la perspectiva de Durkheim, Barba Solano (2011) afirma que:

[...] la cohesión social se refiere a la naturaleza (en nuestros días hablaríamos de características) de los vínculos sociales que permiten a los individuos experimentar un sentido de pertenencia social (en diversas escalas), confiar en los demás (confianza horizontal), reconocer la legitimidad de la sociedad y confiar en sus instituciones.

Por su parte, para la CEPAL (2007) la cohesión social está conformada por el capital social, como patrimonio simbólico de la sociedad en el manejo y construcción de normas, redes y lazos sociales de confianza; integración social, como proceso dinámico que permite a los individuos ser parte del nivel mínimo de bienestar que alcanza una sociedad mediante su desarrollo; inclusión social, como mecanismo que permite la adaptación del sistema a las posibilidades de todos los individuos; y de ética social, como el conjunto de valores, conformación de normas y la solidaridad.

Es así como la cohesión social se puede abordar como un principio político, medio social y fin comunitario, que se circunscribe en la agenda política nacional e internacional para la ejecución de programas y ejecución de presupuestos; se convierte en medio social, puesto que se plantea como factor estructural en las relaciones entre los individuos; $y$ termina siendo un fin comunitario en el que se demarca el sentido de pertenencia hacia un territorio y su cultura. 
La violencia está íntimamente relacionada con la cohesión social, dado que este hecho social influye en la construcción de capital social, en los lazos de solidaridad, en la integración social y en los vínculos sociales en los espacios concretos como los barrios o comunas. En los lugares donde la violencia se normaliza, es cotidianiza, e incluso se legitima, tienden a desaparecer las expresiones comunitarias, a debilitarse el marco político de las relaciones interpersonales, a desconocerse el orden legal (y reconocer el ilegal) y a presentarse la desconfianza entre los habitantes y las instituciones.

\section{La cohesión social, esfuerzo académico por abordar la problemática de la violencia}

En el marco de las experiencias investigativas desarrolladas en América Latina, se pueden encontrar diversidad de estudios de caso relacionados con la cohesión social y la violencia. Al respecto, el estudio de Díaz y Meller (2012), realizado desde una perspectiva teórica, ofrece un marco referencial acerca de la cohesión social en la región continental, comparando las perspectivas que en el tema tienen otras regiones del mundo, tales como, Norteamérica y Europa. El estudio ofrece una conclusión que evidencia una clara diferenciación acerca de la cohesión social, comentando que en América Latina, ésta se basa en aspectos de tipo relacional, más íntimos y de confianza entre vecinos; por su parte, en las sociedades anglosajonas (principalmente), la cohesión social se aborda desde una perspectiva macro-social, relacionada desde el acceso al mercado económico-financiero de consumo y las competencias ciudadanas de convivencia.

Desde otra perspectiva, es decir en un contexto práctico, se pueden encontrar estudios que relacionan la cohesión social y la violencia desde la óptica de la acción institucional, según Dammert (2012), a partir del populismo penal, la coerción institucional y las políticas de seguridad del orden internacional. Dammert y Arias (2007), proporcionan un importante marco contextual al respecto de las acciones que las instituciones realizan para combatir a la violencia y fortalecer la confianza y por lo tanto la cohesión social.

Las principales preocupaciones de los latinoamericanos son la violencia y la pobreza, esto se hace evidente en las encuestas nacionales que se realizan en los procesos electorales. Al respecto, la clase política aprovecha esta situación y consolida sus promesas electorales y sus planes de gobierno para "solucionar" la pobreza y la violencia. En un principio, es una acción lógica que la clase política-dirigencial atienda esta "necesidad" sentida por la comunidad misma, el 
problema es que se aborda la problemática de la violencia -hecho de interés en la presente investigación- a partir de la represión, aumento del poder militar y el sistemático desconocimiento -a veces intencional-de las causas de fondo de la problemática, lo que en palabras de Dammert y Arias (2007), es reconocido como el populismo penal.

Otro tipo de estudios intentan analizar la problemática de la violencia desde la relación existente entre la confianza y la inseguridad. Por ejemplo, Beltrán y Velásquez (2012), realizan modelos de regresión lineal múltiple por medio de mínimos cuadrados ordinarios, con información de las encuestas de victimización y agencias nacionales de estadísticas de los países de Latinoamérica. El estudio concluye que existe una relación directa entre la confianza interpersonal y: la tasa de homicidios, la tasa de urbanización, la desigualdad y la pobreza de manera individual.

Posterior a la evaluación de los modelos, Beltrán y Velásquez (2012) proceden a determinar mediante una expresión aritmética, la relación entre la confianza y la seguridad. Para el desarrollo de este modelo matemático, se toman los datos de la encuesta ECOSOCIAL, promovida por la CIEPLAN. Este estudio concluye que la experiencia de ser víctima está relacionada negativamente con confianza social e institucional, es decir, aquellos que han sido víctimas tienden a confiar menos en otras personas y en sus instituciones. Así mismo la confianza se relaciona negativamente con la percepción de seguridad, pues a menor confianza mayor será la sensación de inseguridad que expresan los habitantes.

Un estudio que complementa el anterior, es el realizado por Serrano y Modrego (2012), en el cual se reflexiona sobre la cohesión social en la región, a partir de las desigualdades territoriales y la forma en que éstas erosionan las dinámicas de cohesión social y, cómo las políticas de desarrollo territorial excluyen a sectores poblaciones $y$, por consiguiente generan desconfianza de los sectores populares en las instituciones.

La desconfianza en las instituciones genera condiciones específicas de gobernanza que no permiten el seguimiento de normas sociales y, por lo tanto, generan escenarios que propician la violencia. Así mismo, Velásquez (2008) establece la importancia de la gobernanza, ya que ésta se puede entender como "una capacidad colectiva adecuada para tomar decisiones con calidad en prevención y seguridad ciudadana". Por su parte, en el contexto de exclusión territorial, la investigación de Serrano y Modrego (2012) muestra la manera cómo la gobernanza ejercida por las instituciones nacionales latinoamericanas lejos de solucionar la problemática de la violencia, la aumenta, ya que se establece: 1. una forma de organizar y gobernar los territorios que favorece una distribución desigual de los recursos, sobre todo en las provincias alejadas del centro del poder 
político-económico; 2. la desarticulación de las instituciones del estado, la empresa privada y la sociedad civil y 3 . la aplicación de políticas del orden coercitivo, penal y criminal que no obedece a los contextos socio-históricos propios de cada cultura, promoviendo así el "populismo penal"

En las anteriores investigaciones se evidencian diversos enfoques, teorías y metodologías con los que se ha abordado la cohesión social y la relación que este hecho social tiene con la violencia, concluyendo (desde una corriente de pensamiento latinoamericano) que la cohesión social desestimula el uso de la violencia, es decir, en sociedades con códigos sociales (extra legalesculturales) que permiten compartir, defender y promover valores sociales, la violencia, sus relatos y actores tienen menor impacto en la sociedad. Lo anterior permite establecer una relación con el hábitat y los factores de vulnerabilidad ante la violencia, ya que el hábitat se construye a partir de las relaciones entre los hombres y estas se consolidan en la confianza generada por los mismos, base fundamental de la cohesión social.

\section{La violencia, un concepto en construcción}

No es simple la tarea de definir la violencia. Conceptos de violencia han sido propuestos para hablar de muchas prácticas, hábitos e incluso disciplinas, hasta el punto tal que todo comportamiento humano podría ser considerado como violencia, incluso aquellas acciones de aprendizaje y formación en la escuela, como por ejemplo la violencia simbólica propuesta por Bordieu (2001), la cual se comete sin que sea percibida como violencia, inclusive por quien victimiza y es victimizada, pues se inserta en la trama de relaciones de poder que son naturalizadas por las personas.

Esta tendencia de conceptuar la violencia, entenderla como un hecho que puede ir más allá de la corporización de daños físicos a las personas, permite entender definiciones como la de Chauí $(1999,3,4)$ que establece que la violencia es:

[...] (1) Todo hecho usando la fuerza para ir en contra de la naturaleza de alguien (es desanturalizar); (2) todo acto de fuerza contra la espontaneidad, la voluntad y la libertad (es obligar, constreñir, torturar, brutalizar); (3) todo acto de trasgresión contra lo que alguien o una sociedad define como justo desde el derecho. Consecuentemente, la violencia es un acto de brutalidad, sevicia y abuso físico y/o psíquico contra alguien y caracteriza relaciones intersubjetivas y sociales definidas por la opresión e intimidación, por el miedo y el terror.

Cualquier noción de violencia es, por sí misma, ambigua. No existe una percepción única sobre lo que es violencia, pero sí pude existir unicidad conceptual sobre la multiplicidad de los 
actos que son violentos, cuyos significados son analizados y comprendidos a partir de las normas y de los contextos sociales. Arblaster (1996, 803-804), considera que:

[...] El término (violencia) es demasiado potente para que un consenso sea posible. No obstante, un entendimiento del término dictado por el sentido común es, a groso modo, que la violencia se clasifica como cualquier agresión física contra los seres humanos, cometida con la intención de causarles daño, dolor o sufrimiento.

De igual manera, Keane (2000) considera que la violencia es aquella interferencia física que un individuo o grupo ejerce sobre el cuerpo de un tercero cuyas consecuencias pueden ir desde una herida hasta el deceso. Igualmente, Varela (2004) razona a la violencia como la expresión más severa y evidente del poder físico, que tiene el propósito de producir daño de forma deliberada contra otras personas, es una agresión que conduce a la reprobación moral, el resentimiento y a la venganza y puede ser ocasionada por actores que van desde un individuo hasta el mismo Estado.

Por su parte, y desde una definición instrumental (oficial), la organización mundial de la salud $(2002,1)$ define a la violencia como "el uso intencional de la fuerza física, amenazada o real, contra sí mismo, contra un tercero, o contra un grupo o comunidad y cuyo resultado es o tiene una gran posibilidad de producir (...) lesiones, muerte, daño psicológico, desarrollo perverso o privación", a su vez, la violencia es tipificada por esta institución si esta es auto-dirigida, interpersonal o colectiva, anulando de esta manera la posibilidad de identificar en la violencia relaciones sociales, circunstancias y mucho menos condiciones históricas.

Por otra parte, Arteaga $(2003,121)$ considera que la violencia "es el resultado de un proceso constante de desorganización social, hecho que afianza la idea de que la violencia es parte estructural de la historia de la humanidad y las civilizaciones"; negando de esta manera la noción de que la violencia sea un hecho coyuntural a los procesos históricos, es decir fortuito y esporádico, que encuentra solución y fin en la refundación de las clases sociales (opresoras y oprimidas) a través del desarrollo como tecnología del crecimiento económico y su lucha contra la pobreza ; siendo más bien, la violencia, un proceso de modificación continuo de la sociedad de difícil aprehensión, que engloba una serie de conflictos sociales, no únicos y mucho menos simples, que demandan el concurso de los presupuestos de varias disciplinas y personas que sustenten como mínimo su explicación.

Desde el punto de vista anterior, se podría asumir que la violencia es un fenómeno complejo, que es inherente a la sociedad y que se configura temporalmente, para Martucelli (2001, 242) es "el residuo estructural constante no institucionalmente tratado, porque no es 
institucionalmente tratable, de un estado histórico de relaciones sociales de dominación. Su existencia revela en cierta medida los límites de lo democrático".

Galtung (1995), agrega que la violencia está presente cuando los seres humanos se ven influidos por la frustración, de tal manera que sus realizaciones afectivas, somáticas y mentales están por debajo de sus realizaciones potenciales, indicando de esta forma la relación existente entre la violencia y las condiciones necesarias para estar bien, sano y ser competente. En donde, por ejemplo se tiende a pensar, que en el momento en que las óptimas condiciones desaparezcan, entonces pululará la violencia.

Es posible evidenciar que la violencia, puede ser causa y efecto de la diferenciación social que permite el establecimiento de estatus, identidades y territorios. Sin embargo, estas definiciones explican las condiciones con las cuales se mantiene la violencia y no las condiciones con las que ésta puede surgir. Uno de las posibles condiciones que permiten explicar el surgimiento de la violencia, según Arteaga $(2003,138)$ es la frustración y el miedo. Por el cual se puede entender como "sensación de vacío frente a una situación de peligro que inhibe la sensación de agresión y pone al individuo en riesgo como estrategia para salir de dicha situación" y está relacionado con la sensación que desea transmitir el agresor hacia la víctima.

\section{METODOLOGÍA}

El presente estudio se realizó en la ciudad de Dosquebradas, la cual se localiza al sur del departamento de Risaralda en el centro-occidente colombiano, en el piedemonte de la vertiente occidental de la cordillera central perteneciente a la macro-cuenca del Río Cauca (Mapa 1). El municipio pertenece al área metropolitana de centro occidente (AMCO) junto con los municipios de Pereira (capital departamental) y La Virginia. A nivel regional, es parte de la subregión I del departamento de Risaralda (municipios del sur risaraldense). 
Mapa 1. Ubicación geográfica de Dosquebradas

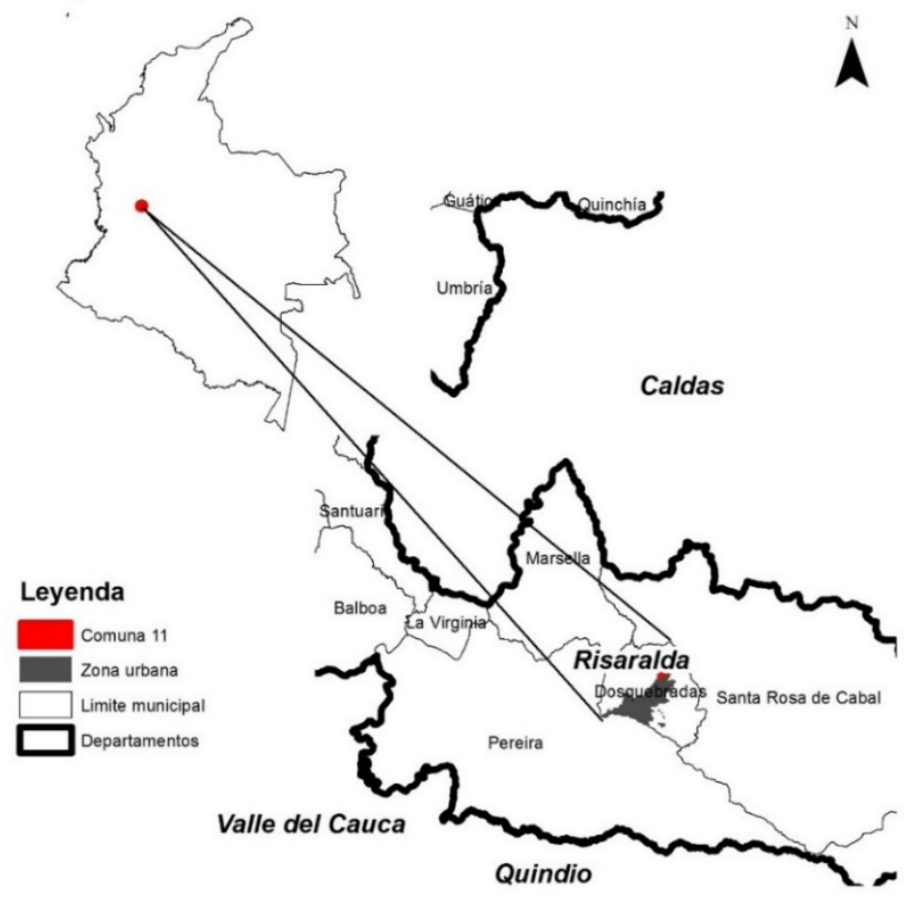

Fuente: elaboración propia

El municipio de Dosquebradas cuenta con una población total, según el DANE (2015) de 198.877 habitantes, representando cerca del $20 \%$ de la población total del departamento; del total de la población del municipio, el 94.73\% vive en el área urbana y el 5.27\% en el área rural. Según las proyecciones del DANE (2015), la población urbana del municipio de Dosquebradas se encuentra creciendo en promedio a razón del 1.21\% anual, mientras que la población rural ha decrecido en $1.41 \%$.

En cuanto a su división político-territorial, Dosquebradas está dividida en 12 comunas (Dosquebradas 2012) (Mapas 1 y 2). El actual estudio se desarrolló en la comuna 11 habitada por 12.353 personas y conformada por los barrios: El Diamante (489 habitantes), La Capilla (1.684 habitantes), Los Naranjos (4.448 habitantes), Santa Teresita (5.633 habitantes) y Siete de Agosto (99 habitantes) (DANE 2015), los cuales tienen como característica particular, ser los barrios más antiguos del municipio. 
Mapa 2. División político territorial por comunas. Dosquebradas, Risaralda

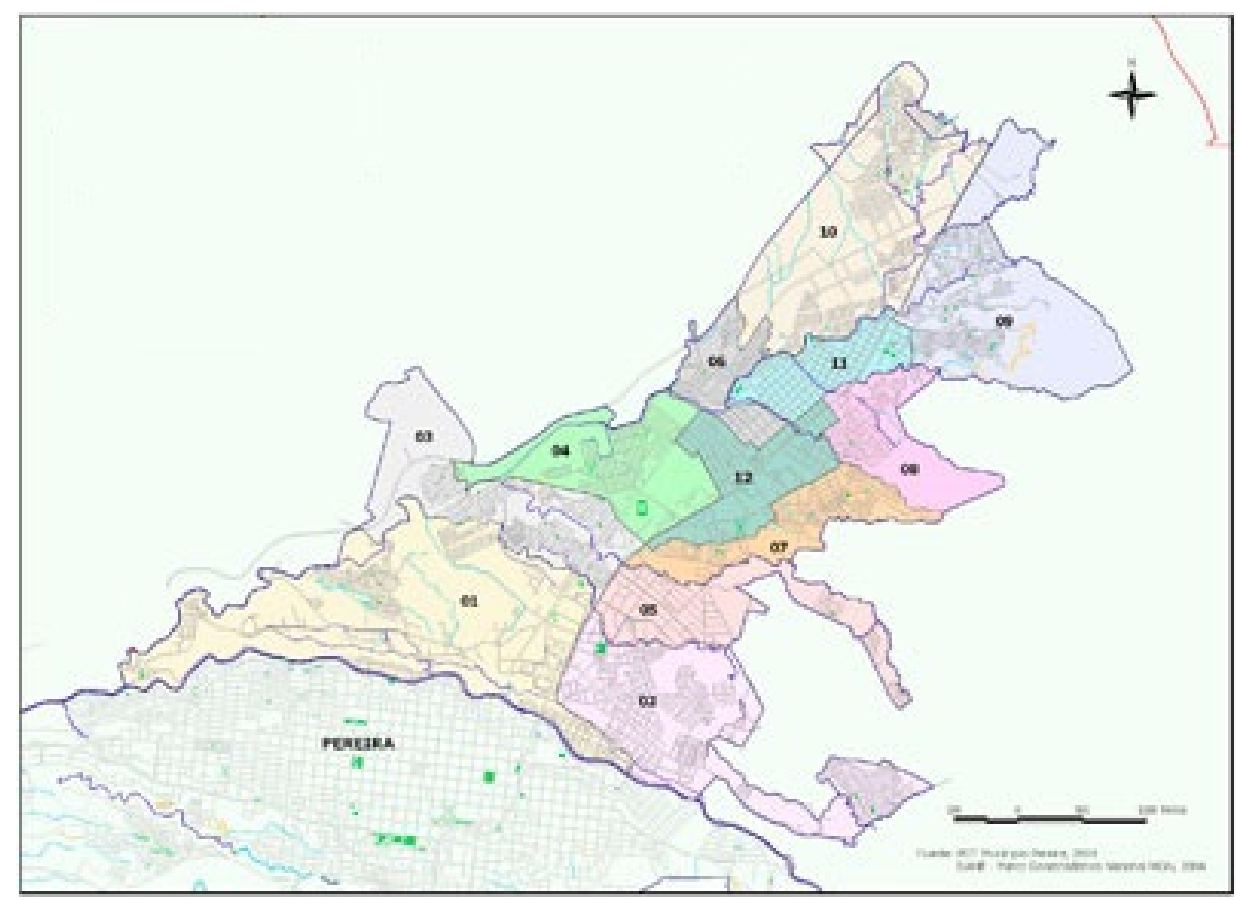

Fuente: Dosquebradas (2012)

En este sentido se mostrará se mostrará el contexto metodológico que permitió la construcción de los indicadores y de las relaciones estadísticas entre los diferentes hechos sociales.

\section{Construcción del índice de cohesión social}

\section{$\underline{\text { La encuesta de victimización y cohesión social }}$}

El objetivo de la encuesta es determinar los aspectos relacionados con la violencia, la victimización y la cohesión social de la comuna 11 de Dosquebradas. La encuesta de 115 preguntas, y basada en parte de la que realizó el DANE (2012b, 2012e), el manual para encuestas de victimización de la oficina contra la droga y el delito de las Naciones Unidas (2010), la cámara de Comercio de Bogotá (2013), la CIEPLAN (2013) y CIEPLAN et al (2007), se divide en seis temas principales: (1) caracterización socio-económica del hogar; (2) percepción de seguridad; (3) identificación de delitos; (4) relación de seguridad y justicia (confianza institucional); (5) victimización y (6) cohesión social.

Los barrios seleccionados para la encuesta fueron los que conforman la comuna 11 de Dosquebradas, Risaralda. La población objetivo fueron las personas que viven en los hogares 
particulares que habitan en la comuna 11, que fueran mayores de 16 años, siendo la unidad de observación los hogares.

La unidad de muestreo y el marco muestral es el mismo utilizado en el articulo Hacía una tipología de lugares peligrosos. Caso de estudio comuna 11 de Dosquebradas" (Jiménez 2014), publicado en esta revista en el Numero 56, Volumen 1, en el año 2014.

\section{Construcción de la victimización, como medida de la violencia}

La victimización, según Briceño-León, Avila y Camardiel (2012, 81) es "un proceso de afectación física, emocional o social sufrida por un individuo" o colectivo (Marchiori 2006) que ha sido víctima de un acto delictivo o no, generalmente por medio de la violencia física o emocional.

En el caso de la comuna 11 se calculó el grado de victimización por medio de la encuesta utilizada en Jiménez (2014), teniendo en cuenta que se relacionaban aquellos hogares que en el último año (2014) tuvieron como víctimas a algún miembro del núcleo familiar de un acto violento (hurtos y homicidios) en alguno de los barrios de la comuna estudiada.

\section{Construcción del índice de cohesión social}

Para la construcción de un indicador de cohesión social se tomó como base la encuesta (1) eco-social de la CIEPLAN (2013), CIEPLAN et al (2007) y (2) el sistema de indicadores de cohesión social propuesto por la CEPAL $(2007,2007)$ las cuales son metodologías adaptadas por estas instituciones y aplicadas para medir el grado de compactación social e identidad existente en países latinoamericanos.

Posteriormente, las respuestas de los encuestados fueron procesadas en el software SPSS, con el fin de construir un indicador de cohesión social en la comuna y demostrar si existe una relación entre la experiencia de victimización y el estado del indicador de cohesión social.

El indicador de cohesión social se divide en dos partes: (1) índice de la calidad de convivencia social (ICSS) y (2) Índice de la calidad de la convivencia política (ICP) (Figura 1, Tabla 1). La ponderación de ambos índices permitió construir el índice de cohesión social. 
Figura 1. Índice de Cohesión social

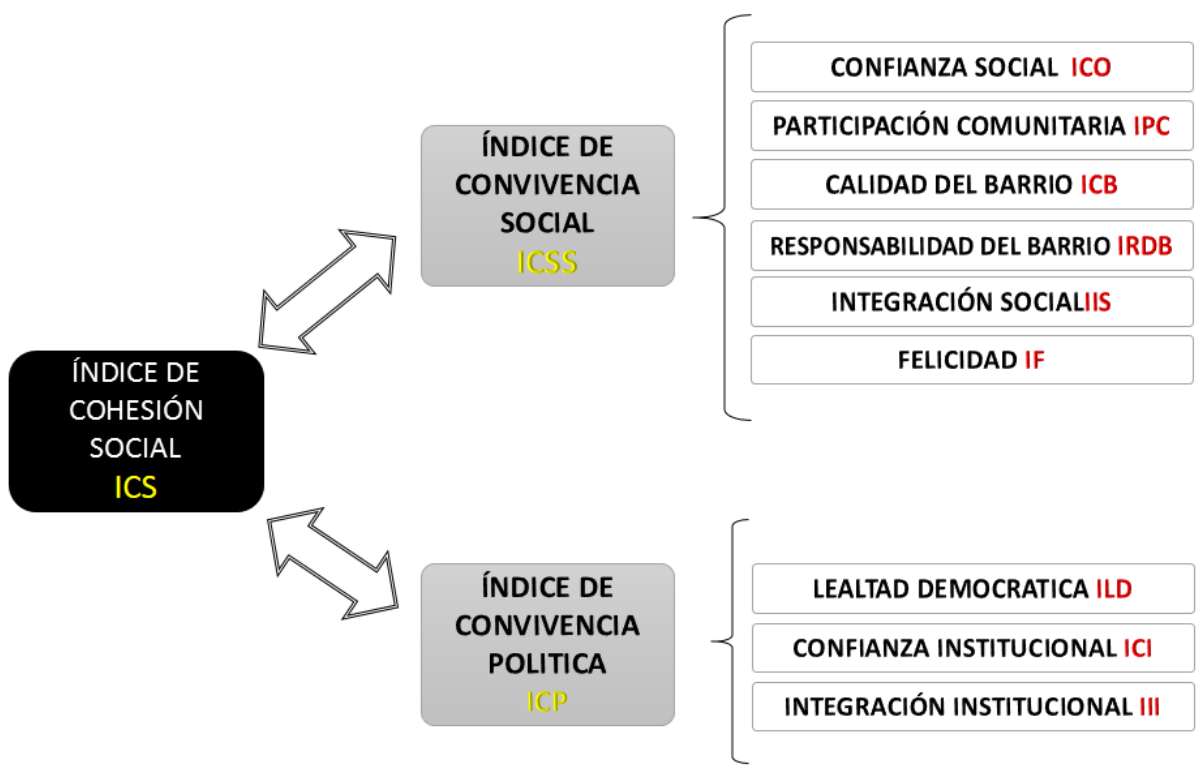

Fuente: Elaboración propia

La elección de estos índices se debe principalmente a cinco factores: (1) la existencia de un precedente de medición en un país latinoamericano; (2) su fácil aplicación metodológica (3); a la pertinencia que tiene la cohesión social con la temática de la violencia; (4) con el fin de encontrar una relación estadística entre el nivel de cohesión social en la comuna 11 y las experiencias de victimización; y (5) con la intención de innovar y adaptar metodologías alternativas para la medición de los impactos de la violencia en el contexto local.

Este índice permite medir el grado de compactación e identidad social que tienen los pobladores (entre sí) de la comuna 11 del municipio de Dosquebradas. Ofrece una medida indirecta de la calidad de las relaciones sociales, el estado de la confianza social, la participación comunitaria, la calidad del barrio, la gestión comunitaria, la integración y el apego al barrio, así como el estado de la percepción sobre la democracia local y el grado de articulación, aceptación y de confianza social generado por las instituciones estatales en los pobladores locales.

\section{Sub-índices}

Para construir el índice de cohesión social, se evaluaron 9 sub-índices que lo componen, formulando las preguntas a cada uno de los hogares encuestados. Estos sub-índices se encuentran clasificados en la Tabla 1 y se componen de mínimo una y máximo cuatro frases/preguntas: 
Tabla 1. Índice de cohesión social. Sub-índices que lo componen

\begin{tabular}{|c|c|c|c|}
\hline \multicolumn{2}{|r|}{ Preguntas índice de Convivencia social } & \multicolumn{2}{|c|}{ Preguntas índice de Convivencia Política } \\
\hline \multirow{2}{*}{$\mathrm{ICO}$} & $\begin{array}{c}\text { (1) Se puede confiar en la mayoría de las } \\
\text { personas o (2) hay que tener cuidado de } \\
\text { ellas }\end{array}$ & \multirow{2}{*}{ ILD } & $\begin{array}{l}\text { actor que administraría mejor su } \\
\text { barrio, el máximo responsable }\end{array}$ \\
\hline & $\begin{array}{l}\text { (1) la mayoría de la gente actúa } \\
\text { correctamente con uno o (2) la mayoría } \\
\text { trata de aprovecharse }\end{array}$ & & $\begin{array}{l}\text { los derechos de las personas se } \\
\text { deben respetar }\end{array}$ \\
\hline IPC & $\begin{array}{c}\text { Intención de participación en (1) } \\
\text { Asociaciones de tipo deportivo, (2) Juntas } \\
\text { de Acción Comunal (JAC), (3) } \\
\text { Organizaciones religiosas y (4) partidos } \\
\text { políticos. }\end{array}$ & $\mathrm{ICl}$ & Confianza en las instituciones \\
\hline $\mathrm{ICB}$ & $\begin{array}{l}\text { Satisfacción condiciones de seguridad de } \\
\text { equipamientos colectivos }\end{array}$ & \multirow{4}{*}{ III } & $\begin{array}{l}\text { La gente que dirige el país no le } \\
\text { importa lo que le pase a las personas } \\
\text { como uno }\end{array}$ \\
\hline IRDB & $\begin{array}{l}\text { Responsabilidad de las instituciones } \\
\text { formales }\end{array}$ & & $\begin{array}{c}\text { las autoridades no harían nada si } \\
\text { hubiera un problema grave en mi } \\
\text { barrio o vecindario }\end{array}$ \\
\hline \multirow{3}{*}{ IIS } & $\begin{array}{l}\text { Lo que yo piense no le importa mucho a } \\
\text { nadie }\end{array}$ & & $\begin{array}{l}\text { la mayor parte de las personas con } \\
\text { poder solo tratan de aprovecharse } \\
\text { de personas como yo }\end{array}$ \\
\hline & $\begin{array}{l}\text { Que me dejan al margen de las cosas } \\
\text { importantes }\end{array}$ & & $\begin{array}{l}\text { las intervenciones del barrio se debe } \\
\text { hacer conjunta o sectorialmente }\end{array}$ \\
\hline & $\begin{array}{l}\text { La gente que me rodea haría poco por } \\
\text { ayudarme si me pasara algo }\end{array}$ & & \\
\hline $\mathrm{IF}$ & $\begin{array}{c}\text { Grado de felicidad expresado por la } \\
\text { persona }\end{array}$ & & \\
\hline
\end{tabular}

La ponderación de los índices

Un punto de partida para la construcción del índice de cohesión social fueron las metodologías empleadas en las experiencias de la CIEPLAN (2013), la CEPAL $(2007,2007)$ y del programa EUROSOCIAL (2013).

Se debe tener en cuenta que los valores de ponderación son asignados de acuerdo al impacto de las respuestas con referencia a la temática de la cohesión social. Teniendo en cuenta el marco teórico de la cohesión social y su relación con la construcción de hábitat, se decidió asignar los valores más altos a las repuestas que favorecían la convivencia social y política, y por lo tanto, los valores más bajos a los que no favorecían dichas condiciones.

En todos los índices, se escogen valores de ponderación altos para las respuestas que favorecen la cohesión social y bajos para las que no. En los casos en los que las opciones de 
respuesta son dos, se ponderan con "3" (valor máximo) y "1" (valor mínimo); cuando las posibilidades de respuesta son tres, se ponderan "3" (valor máximo), "2" (valor medio) y "1" valor mínimo". Lo anterior con el fin de establecer una escala de comparación similar para todos los subíndices.

En todos los casos, es preciso indicar que el parámetro de ponderación y posterior clasificación en rangos de las sumatorias para sub-índices e índices, se determinó, adaptó y aplicó para el presente estudio siguiendo estos referentes: (1) El estudio de Arriagada y Sepúlveda (2002) en el que se estableció, para un estudio similar, la escala valorativa de nivel alto, medio y bajo para ponderar el índice de cohesión social y (2) el cálculo de los límites de los niveles alto, medio y bajo a partir del valor medio o central. En este caso, se calcula el valor medio de cada límite y se crean tres rangos simétricos y equidistantes de este valor central (alto, medio y bajo)

Luego de clasificar y agrupar los sub-índices en los niveles: alto, medio y bajo, se procedió a asignarles valores con el fin de hacerlos comparables en una misma escala numérica para construir los índices de convivencia social, convivencia política y cohesión social, realizando las siguientes operaciones. Se seleccionaron los valores de ponderación "3" (nivel alto), "2" (nivel medio) y "1" (nivel bajo), los cuales fueron escogidos de manera tal que permitieran evaluar el estado de la cohesión social, dónde las respuestas o enunciados que favorecían tal condición fueron ponderadas con los valores más altos. Para el desarrollo de este índice se realizaron los siguientes pasos:

Cada entrevistado (94 en total) tiene la clasificación de nueve subíndices (Tabla 1) en niveles alto, medio y bajo.

Se sumaron los valores de cada subíndice obteniendo una escala que va desde 94 hasta 282 para cada subíndice.

Se clasificaron los sub-índices en tres niveles de acuerdo al criterio de valor central y equidistancia expuesto anteriormente. En el presente caso quedo así: Nivel alto $\Sigma=221$ a 282 , nivel medio $\Sigma=158$ a 220 y nivel bajo $\Sigma=$ menor que 157 .

Luego de tener 9 sub-índices, 6 para convivencia social y 3 para convivencia política, se vuelven a clasificar de acuerdo a cada índice. Por ejemplo: (1) los 6 sub-índices de ICS se suman, obteniendo una sumatoria de 18 y se clasifican de acuerdo al criterio de valor central y equidistancia, en este caso los rangos fueron: Nivel alto $\Sigma=15$ a 18, Nivel Medio $\Sigma=11$ a 14 y Nivel bajo $\sum=$ menores que 10, y (2) los 3 sub-índices de ICP se suman, obteniendo una sumatoria de 9 y 
se clasifican aplicando el mismo criterio, en este caso los rangos fueron: Nivel alto $\Sigma=8$ a 9, Nivel Medio $\Sigma=6$ a 7 y Nivel bajo $\Sigma=$ menores que 5

Finalmente, para obtener el índice general de cohesión social, se toman los 9 sub-índices (sin separarlos en convivencia social y convivencia política), se suman obteniendo una sumatoria de 27, luego se clasifican de acuerdo al criterio de valor central y equidistancia, quedando los niveles así: nivel alto $\Sigma=23$ a 27 , nivel medio $\sum=17$ a 22 y nivel bajo $\Sigma=$ menor que 16 .

\section{Relación estadística sobre el nivel cohesión social y la victimización}

Finalmente, se realizó una prueba estadística $\left(X^{2}\right)$ para confrontar la relación entre la victimización y el nivel de cohesión social de cada encuestado, cuya hipótesis determinaba la existencia de una relación positiva entre el hecho de haber sido víctima de algún delito violento durante el último año y el nivel de cohesión social presentado por cada hogar dentro de la comuna 11.

\section{RESULTADOS}

\section{La realidad de la comuna 11 , entre la desconfianza social y la violencia}

Se va a tomar la violencia homicida como parámetro para ofrecer una mirada del contexto de la violencia en el área de estudio de la presente investigación. Se plantea este tipo de violencia ya que este suceso suele conmocionar a los ciudadanos e investigadores más que cualquier otro acto de violencia, de hecho y siendo más precisos, las naciones y sus cuerpos de investigaciones tienden a comparar la violencia a partir de las tasas de homicidios; las cuales son promedios agregados para una extensión territorial, anotando que por sí mismas, estas tasas no reflejan la distribución espacial de estos delitos, ni permiten entender las causas de los mismos, pero son un insumo básico para poder comparar diversos fenómenos².

Tradicionalmente el AMCO ha tenido una tasa de homicidios mayor a la media del país, siendo críticos los años 2005 y 2008 donde se dobló esta relación con respecto a la nación (Figura 2). Igualmente, es posible evidenciar que de las áreas metropolitanas que históricamente registran

\footnotetext{
2 Es claro que estas tasas no representan el único medio para entender la problemática, es más esta propuesta problematiza el hecho de que las tasas por sí mismas no son la única explicación, son apenas un instrumento de medición que puede orientar o no, la dirección de la investigación.

Para el presente contexto dela investigación se muestran los años 2004-2013, dado la disponibilidad de información por parte de Medicina Legal.
} 
más homicidios son las del Valle de Aburrá, Cali y el AMCO, siendo que durante el periodo 20042008 está última lideró los índices de decesos violentos (Figura 2). SI bien, desde el 2004 todas las entidades territoriales han venido disminuyendo ostensiblemente sus tasas (excepto Cali), llama la atención los altos registros que posee el AMCO con respecto a las otras áreas metropolitanas (Figura 2) y el hecho de que todos los entes territoriales, inclusive Bogotá que ha tenido históricamente la tasa más baja, superan los límites que ha establecido la OMS y que categorizan al homicidio como una pandemia dentro de estas sociedades.

Figura 2. Evolución de las tasas de homicidios en Áreas metropolitanas y en Colombia, 2004-2013

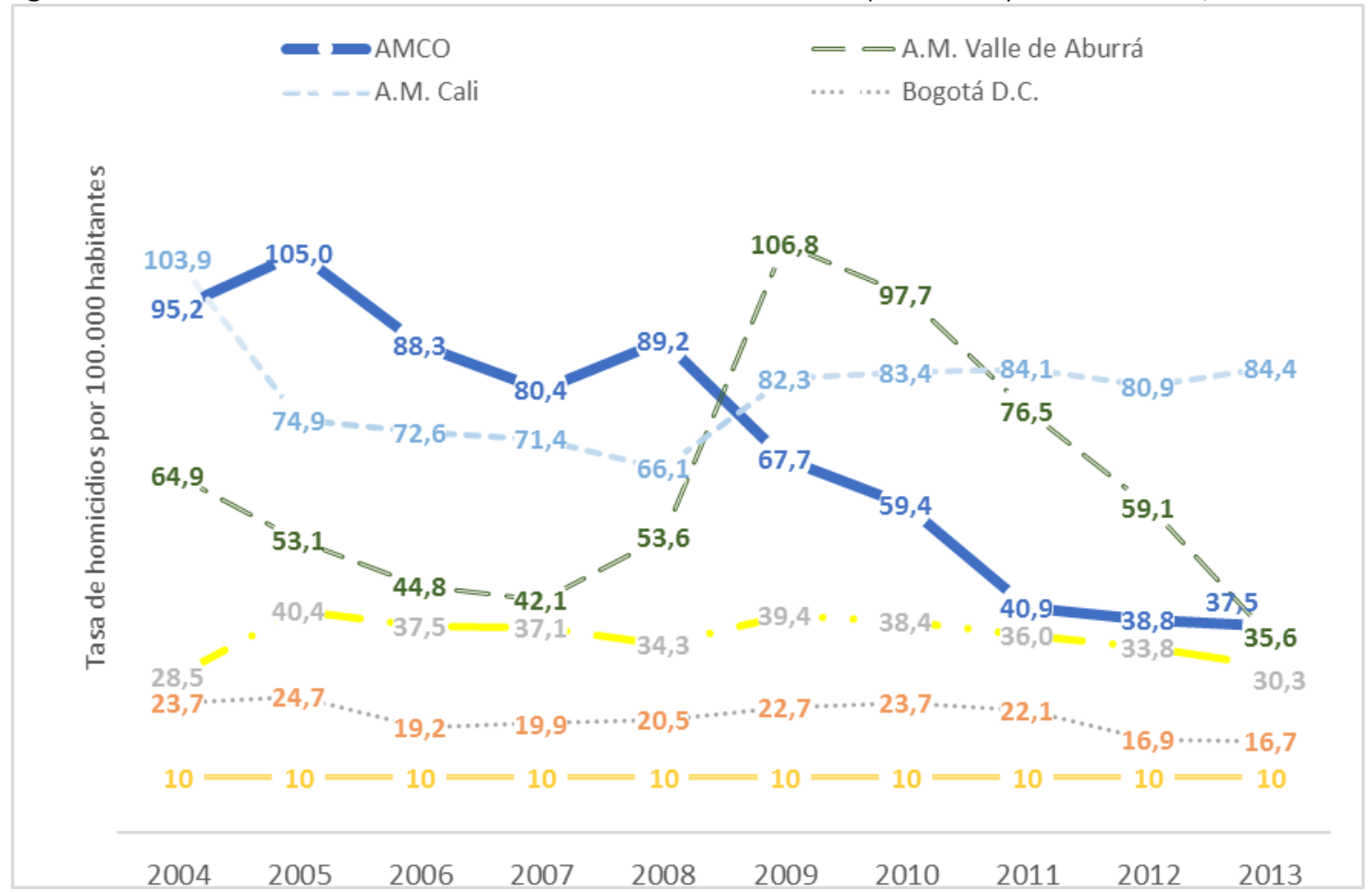

Fuente: elaboración propia con datos de Instituto de Medicina Legal y Ciencias Forenses (2015)

En cuanto a las ciudades del AMCO es posible evidenciar que las cuatro tienen una importante disminución de sus tasas desde el año 2004 (Figura 3), sin embargo es difícil definir un patrón de reducción del homicidio. Las ciudades que registran mayores tasas son La Virginia y Santa Rosa de Cabal, sin embargo las que concentran la mayor cantidad de homicidios son Pereira y Dosquebradas. Todas las ciudades tienden a superar la media del AMCO con excepción de Dosquebradas (Figura 3). 
Figura 3. Tasas de homicidio ciudades del AMCO, 2004-2013

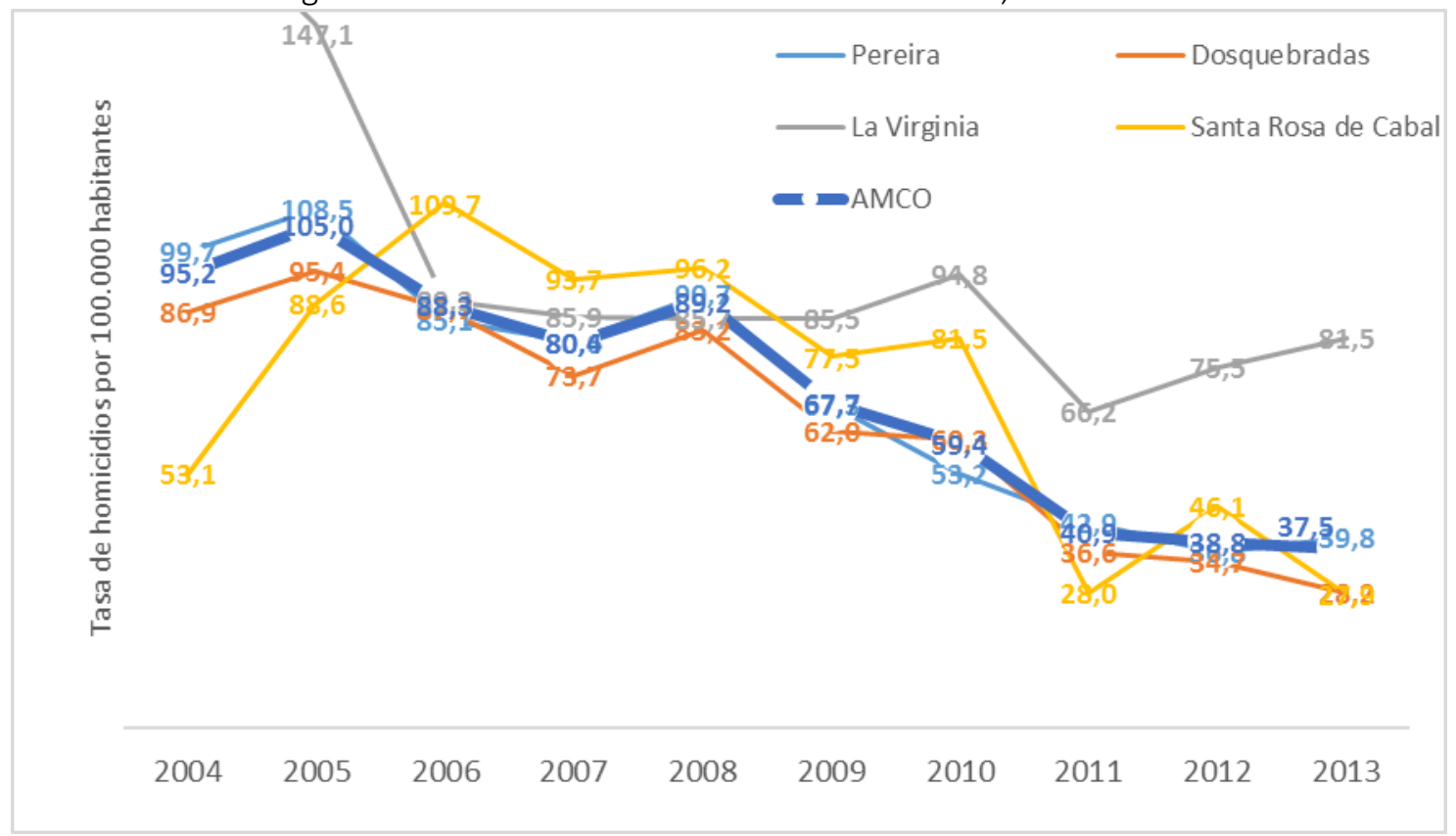

Fuente: elaboración propia con datos de Instituto de Medicina Legal y Ciencias Forenses (2015)

Como se puede evidenciar en las Figuras 2 y 3, el AMCO y el municipio de Dosquebradas, tradicionalmente, al menos en los últimos 10 años, ha liderado con sus altos registros las tasas de homicidios del país, situación que lleva en el siguiente apartado a plantear la necesidad de realizar un estudio de violencia en este territorio, y que permitió, a su vez, configurar la pregunta de que relaciona los indicies de cohesión social con la victimización.

\section{Acerca de la cohesión social, los resultados en campo}

\section{Acerca de la convivencia social}

Confianza social

En cuanto al nivel de confianza hacia las personas, se encuentra que $64,9 \%$ de los entrevistados afirman no confiar en las demás personas, así como el 72,3\% afirma que las personas, en este caso sus vecinos, tratan de aprovecharse de ellos. Ponderando las anteriores respuestas es posible indicar que el $64,9 \%$ de los entrevistados tienen un ICS bajo, $21,3 \%$ medio y 13,8 bajo (Figura 4), lo que permite decir que el ICS de la comuna es bajo (140) (Figura 5).

Demostrando que en los barrios existe una desconfianza en el vecino, explicando porque se presentan cada vez más conflictos de convivencia en los barrios, pues la desconfianza en el este 
cercano par, lleva al desconocimiento y por lo tanto a su prevención con el mismo. Este grado de desarticulación social, se traduce en un factor de vulnerabilidad que les ofrece a delincuentes encontrar un escenario donde no puedan establecerse redes de apoyo y por lo tanto que cometer delitos sea menos riesgoso (en cuanto al ofensor) para su aprehensión y, sea la actividad delictual más eficiente, más efectiva.

\section{Participación comunitaria}

El interés de participación que tiene la población en actividades de promoción de calidad de vida a partir de la asociatividad comunitaria, permite establecer el valor cívico que tienen las personas y el grado de identidad que poseen hacia sus instituciones basales, lo cual constituye una mirada acerca de las formas como los pobladores asumen la gestión de sus proyectos comunales y de hábitat colectivo.

Este índice muestra que la población tiene poco interés en participar en grupos de acción comunitario, ya que $84,4 \%$ de los entrevistados exponen este juicio (Figura 4), de igual forma $48,9 \%$ de los entrevistados tienen un nivel bajo de ICP, $21,3 \%$ un nivel medio y $29,8 \%$ un nivel alto, lo que permite decir que la comuna 11 tiene un ICP bajo (170) (Figura 5).

Esta situación genera un inconveniente en la construcción social de políticas sociales endógenas que garanticen la convivencia, el empoderamiento y consoliden una identidad que promueva la acción comunitaria en aspectos como el cuidado y buen uso del espacio público, la cultura ambiental y la seguridad en el barrio. Pues, la participación en el fomento y desarrollo de estos grupos culturales permite profundizar el arraigo cultural e identitario hacia el barrio, la solidaridad entre vecinos, el establecimiento de metas y objetivos comunes entre los vecinos, el apoyo ciudadano y las redes de vigilancias comunitarias.

\section{Calidad del barrio}

Con el fin de generar una evaluación indirecta de la calidad del barrio desde la prestación de servicios públicos y equipamientos colectivos, se realizó una serie de cuestionamientos sobre algunos de esos servicios dentro del barrio, tales como: entorno de las instituciones educativas, servicio de salud, agua y alcantarillado, mantenimiento del espacio público, transporte público, y la policía nacional. 
Luego de ponderar las respuestas que otorgaron los encuestados, se puede evidenciar que la calidad del barrio, según sus habitantes, corresponde a un nivel medio de calidad, ya que $42,6 \%$ de los entrevistados lo califican de esta manera, mientras que $11,7 \%$ de los entrevistados consideran que el nivel de calidad es bajo (Figura 4); lo anterior establece que el ICB para lo comuna 11 es medio (220) (Figura 5).

Lo anterior representa que nueve de cada diez habitantes aceptan y se conforman con las condiciones físicas de los equipamientos, con los servicios públicos prestados (en ocasiones a partir de la autogestión) y con el entorno exterior de las instituciones educativas y las condiciones de seguridad del barrio; por otro lado, una tercera parte expresa su inconformidad con equipamientos y servicios y aclara que es necesario mejorar de manera mediata los ítems descritos anteriormente.

Responsabilidad por el desarrollo del barrio

La responsabilidad que tienen los actores comunitarios en el manejo del barrio determina el grado de compromiso sentido y adquirido por cada agente. En términos generales, los encuestados expresan que todos los agentes tienen altos niveles de responsabilidad en el manejo del barrio. Los niveles más altos de responsabilidad otorgados por la comunidad en el manejo del barrio son la alcaldía (98,9\%), la Policía Nacional de Colombia (94,7\%), la Junta de Acción Comunal (92,6\%), los vecinos (86,2\%), el Área Metropolitana de Centro Occidente $(79,8 \%$ ) y los delincuentes del barrio $(74,5 \%)$.

Resulta interesante revisar la inclusión que hacen los pobladores de los "delincuentes del barrio", también conocidos como "los vagos, campaneros, ninis, gamines o consumidores", donde el $74,5 \%$ de los encuestados reconocen a estas personas como agentes (con responsabilidades asumidas y por asumir) en la construcción del hábitat, pues si bien, su accionar a veces puede generar más inseguridad, se debe tener en cuenta que los integrantes de estos grupos, son también hijos, padres, hermanos o amigos de los encuestados, en pocas palabras también son habitantes del barrio y por ende son constructores del hábitat.

En cuanto al índice de responsabilidad, se evidencia que el $91,5 \%$ de los pobladores lo ponderan en un alto nivel y el 8,5\% en un nivel medio de responsabilidad en el desarrollo del barrio (Figura 4), lo que indica que el IRDB para el barrio es alto (274) (Figura 5). Lo anterior permite asegurar que los pobladores tienen claro que las decisiones y acciones que se llevan en el barrio son responsabilidad de todos los agentes y no en particular de algunos pocos. Sin embargo, es 
interesante conocer cuanta de esa responsabilidad se traduce en acción efectiva al momento de convocar reuniones comunitarias, convites y juntas de acción comunal.

Integración social

El índice de integración social se compone de tres partes, cada una compuesta por una afirmación de exclusión y cuestionadas de manera independiente: "mis pensamientos no importan al resto de las personas", "me dejan al margen de las decisiones políticas" y "mis vecinos me ayudarían en caso de necesitarlo". Lo que permite medir la percepción que tienen los habitantes en el apoyo y reconocimiento de su rol como agente constructor del hábitat dentro del barrio. La situación que describe el nivel alto, es decir la confianza de que ideales son tomados en cuenta, decisiones políticas que recogen las opiniones propias y posibilidad de apoyo social, es manifestada por el 9,6\% de los encuestados, por su parte el $11,7 \%$ siente que alguna de las anteriores situaciones no se presenta (nivel medio) y el 78,7\% pondera un nivel bajo de integración social, es decir manifiesta ser marginado y no sentir el apoyo, mostrando así un estado de desprotección ante la defensa de sus ideas y el apoyo en contingencias (Figura 4), dando como resultado que para la comuna 11 el IIS es bajo (123) (Figura 5).

Felicidad

En esta parte de la entrevista, se les preguntó a las personas cómo se sienten en el barrio a partir del bienestar que le genera vivir en este hábitat. Lo anterior permite medir el grado de identidad con el territorio, el grado de apego y la felicidad que le genera a la persona construir su hábitat, educar a su familia y poseer bienes materiales en este espacio socio-geográfico llamado barrio. El 70,2\% de las personas expresan sentir felicidad en el barrio que habita, el $25,5 \%$ argumenta estar resignado en este barrio y el $4,3 \%$ dice no estar feliz en el barrio que habita y expresa que al tener la oportunidad de mudarse lo hará (Figura 4), ponderando para la comuna 11 un IF en nivel alto (250) (Figura 5).

Lo anterior demuestra que a pesar de la tensión social que genera la delincuencia, los pobladores tejen vínculos afectivos en el hábitat, en una expresión de topofilia, pero relacionada con el dolor que generan las pérdidas económicas y de vidas, en este sentido y tomando a la topofilia como ejemplo, se plantea que existen condiciones en el hábitat y en sus pobladores como 
topo-doloris y topo-metus (dolor y miedo), haciendo alusión a que a pesar de lo hostil que resulta el barrio para vivir, las personas continúan queriéndolo y reconociéndolo como propio.

\section{Acerca de la calidad la convivencia social}

Lealtad democrática

Para estimar el nivel de lealtad democrática, se ha combinado dos cuestionamientos, el primero determina una referencia a la forma de gobierno, y el segundo, a las condiciones y garantías en el respeto de los derechos humanos y constitucionales. En cuanto a la forma de gobierno, se obtuvo que el $61,7 \%$ de los entrevistados opinan que la administración del barrio la debe hacer la alcaldía municipal, pues fue elegida por los ciudadanos y representa sus intereses, reconociendo el valor de la democracia.

El segundo componente del índice de lealtad democrática es la percepción acerca del respeto de los derechos humanos y constitucionales. En el Estado social de derecho es fundamental, para este régimen democrático, la consolidación de las libertades individuales con base en el reconocimiento de sus derechos fundamentales. Para este estudio, se encontró que el $78,7 \%$ de las personas entrevistadas afirman que a todas las personas, sin importar sus condiciones sociales y sus actos, se les deben respetar sus derechos, demostrando de esta manera un reconocimiento por parte de los habitantes entrevistados a los valores democráticos de la igualdad social.

Por el contrario, el $21,3 \%$ de los entrevistados afirma que los derechos deben ser respetados en la medida que el individuo se gane ese reconocimiento, en otras palabras, a las personas que no cumplan con sus deberes y que además en su actividad lesione intereses vitales, no se deben beneficiar con los derechos de las demás personas.

La ponderación de las anteriores variables permite la construcción del índice de lealtad democrática. Se puede observar que el $48,9 \%$ de las personas tienen una alta lealtad a la forma de gobierno y reconocen los derechos individuales (Figura 4). Por otro lado, el $40,4 \%$ de los entrevistados se clasifican en un nivel medio de lealtad democrática (Figura 4), pues si bien reconocen libertades individuales, afirman que las formas de gobierno autárquicas deben ser las implantadas en sus barrios. Lo anterior (luego de ponderad) permite indicar que el ILD para la comuna 11 es alto (224) (Figura 5). 
Confianza en las instituciones

Para determinar el grado de convivencia política, es importante revisar el nivel de confianza y legitimidad social que expresan los individuos a sus instituciones del orden democrático. Para este caso, se evaluaron el nivel de confianza de la gestión de la presidencia de la República, el Congreso, la Gobernación del Risaralda, la Asamblea Departamental, la Alcaldía Municipal, el Concejo Municipal, Policía Nacional de Colombia, los partidos políticos y los jueces de la República.

En cuanto a la institución que más nivel de confianza tiene entre los pobladores es la Alcaldía municipal de Dosquebradas, ya que el $27,7 \%$ de los pobladores le confieren alta confianza en la gestión administrativa, seguida por la Policía Nacional de Colombia, pues el 17,0\% de los entrevistados le manifiestan alto nivel de confianza y la gobernación de Risaralda y la presidencia de la República ambas con 14,9\% de las personas expresando la alta confianza en sus gestiones.

Por otro lado, las instituciones con menores niveles de confianza otorgados por los entrevistados, es decir nivel bajo: son Congreso de la República (84,0\%), jueces de la República (78,7\%), partidos políticos (77,7\%), Asamblea Departamental (75,5\%) y Concejo Municipal $(66,0 \%)$. Los anteriores entes administrativos y políticos obtienen bajos niveles de confianza por sus pobladores, debido a las constantes denuncias de casos de corrupción, particularmente difundida y practicada en las ramas legislativa y judicial en los órdenes nacional, regional y municipal.

Los anteriores niveles de confianza se ponderaron y permitieron construir un índice global de confianza en las instituciones y por lo tanto aprobación y legitimación social a sus gestiones. En general existe un alto grado de desaprobación, de malestar colectivo en cuanto a la gestión realizada por este conjunto de instituciones. Tres cuartas partes de la población (78,7\%) otorgan bajos niveles de confianza a las instituciones (Figura 4), dando como resultado un nivel bajo de ICI para la comuna (118) (Figura 5).

Lo anterior pone de manifiesto el grado negativo de percepción que tienen los pobladores hacia los políticos o tecnócratas, pues en la mayoría de los casos, los consideran como corruptos, delincuentes y los mayores responsables de las críticas condiciones de seguridad y desigualdad social del país. Sin embargo, llama la atención que la mayoría de cuerpos administrativos y legislativos que componen estas instituciones, son elegidos popularmente. 
Integración institucional

El índice de integración institucional permite medir la distancia (vertical) existente entre la comunidad, las instituciones y el grado de confianza en las acciones de los funcionarios públicos. El $78,7 \%$ de los entrevistados afirman que si ocurriese algún problema grave en el barrio, las actuales autoridades no harían nada para darle solución, lo cual mide el bajo grado de apoyo institucional que perciben estos habitantes. Así mismo el 93,6\% dice que la mayor parte de los políticos intentan sacar provecho de las condiciones económicas y culturales de un grueso parte de la población, indicando la confianza que se tienen en los tecnócratas.

El $62,8 \%$ asevera que los lineamientos generales, programas y actividades del plan municipal de desarrollo 2012-2015 Dosquebradas empresa de todos, no los identifica y no alcanzan a cumplir las expectativas surgidas con la elección de la actual administración municipal, mostrando de esta manera en la mayoría de los encuestados, la inconformidad que se tiene acerca de la gestión pública local.

Finalmente, el 18,1\% asegura que las obras sociales o físicas que se desarrollen en el barrio se deben hacer de manera sectorial diferenciada, es decir sólo la administración pública las debe diseñar y ejecutar, sin el concurso de los habitantes, sin embargo el 81,9\% dice que estas obras deben ser en su totalidad realizadas de manera conjunta, pues el trabajo comunidadadministración municipal afianza la territorialidad, la identidad y por lo tanto garantiza la apropiación, protección y continuidad de las obras.

Ponderando las cuatro respuestas a las afirmaciones anteriores, se obtiene el índice de integración institucional, que para el caso de la comuna 11 es bajo (145) (Figura 5), donde el 17,0\% de los encuestados ponderan un nivel de integración alto (Figura 4), es decir confían en las intenciones de los tecnócratas, se identifican con el programa de gobierno y creen en una articulación institución-comunidad. El 20,2\% tienen un nivel de integración medio y el 62,8\% un nivel bajo (Figura 4), debido fundamentalmente a la desconfianza, a la corrupción institucional y al poco interés de desarrollar acciones y obras que generen bienestar colectivo, en otras palabras al individualismo

Resultados de los índices de Convivencia social, Convivencia política y Cohesión Social 
En cuanto a los índices, se observó que la mayoría de los subíndices fueron clasificados en un nivel bajo, superando incluso la mitad de la valoración (50\%), tal es el caso de los sub-índices ICS, IPC, IIS, ICI, III (Figura 4). Mientras que los índices ILD, IF, IRDB obtuvieron en su mayoría una valoración alta (Figura 4).

Figura 4. Resumen sub-índices de cohesión social (porcentajes)

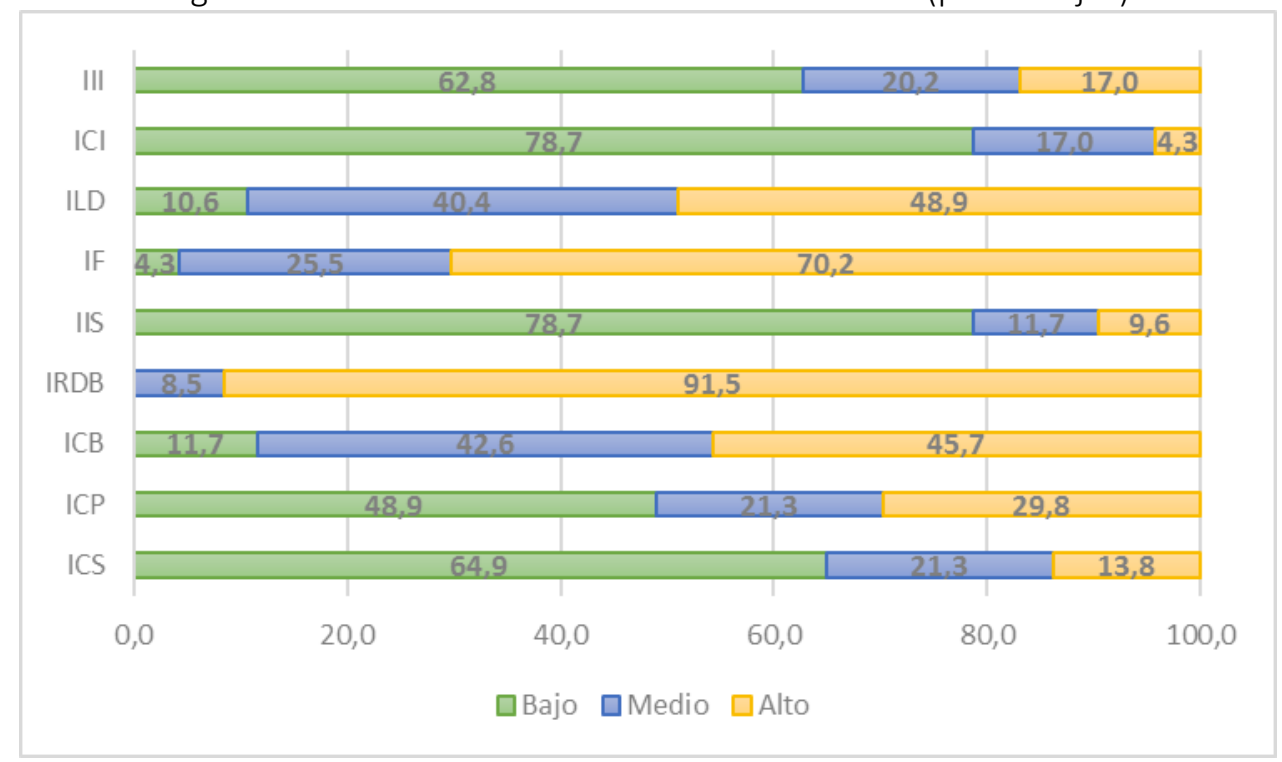

Fuente: elaboración propia

Figura 5. Resumen de Sub-índices

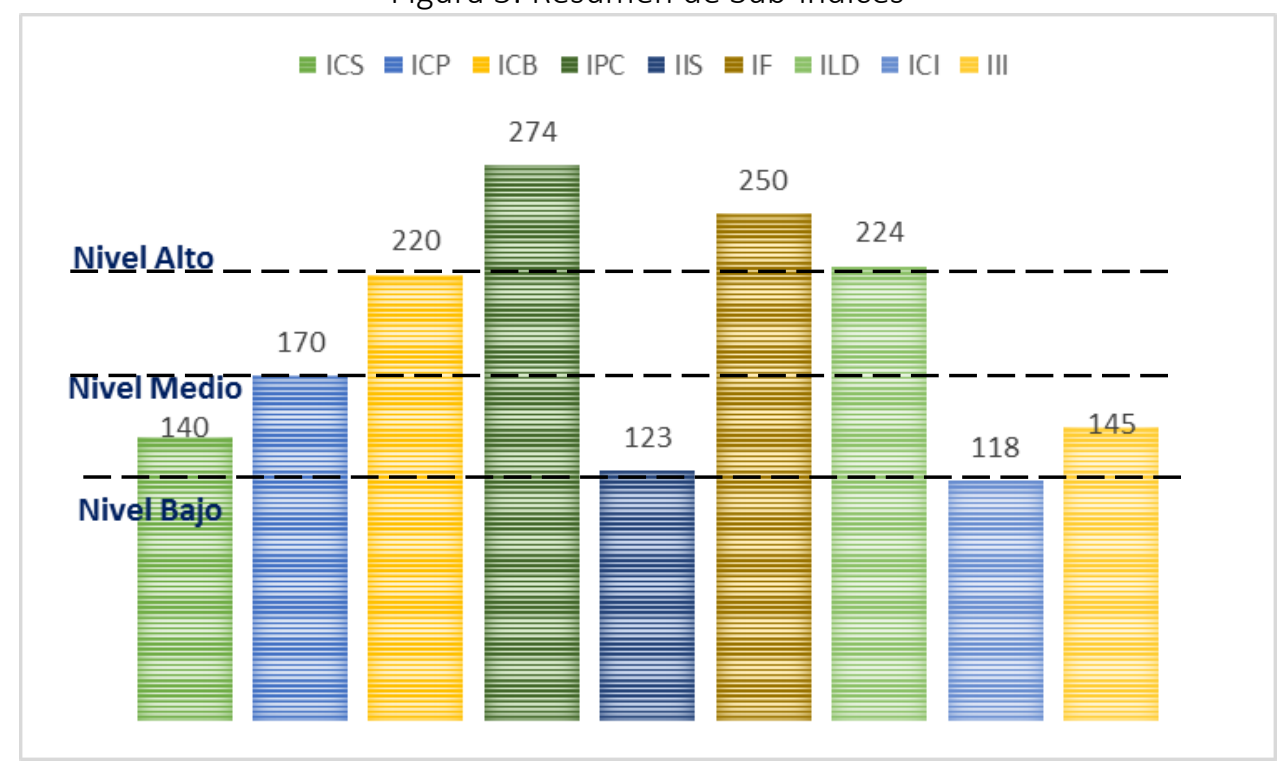

Fuente: elaboración propia

Los sub-índices que tuvieron un nivel bajo fueron ICS, IIS, ICl e III, un nivel medio ICP ICB y un nivel alto IPC, IF e ICl (Figura 5). Los primeros seis sub-índices (de izquierda a derecha) de la 
Figura 5 conforman el índice de convivencia social, el cual para la comuna 11 es medio (12), y los tres últimos sub-índices conforman el índice de convivencia política, que para la comuna 11 es bajo (4), finalmente, al sumar los nueve sub-índices se halla el índice de cohesión social, el cual para la comuna es bajo (16).

La relación entre la cohesión social, vulnerabilidad y hábitat

La cohesión social se compone según CEPAL (2007) de capital social, integración social, inclusión social y ética social. El capital social se encuentra representado por el estado normativo, las redes y lazos sociales de confianza de una sociedad. En cuanto al presente estudio, se evidencia que no existen los lazos sociales de confianza, al igual que las personas sienten poca identidad hacia el conjunto de normas y valores políticos.

Por su parte, la integración social, entendida como la provisión de un mínimo de bienestar social sustentado en (1) los valores socio-culturales básicos para garantizarla, (2) en las condiciones físicas del espacio y (3) a la provisión de servicios, se encuentra que en la comuna 11, no existe una integración social sólida que garantice, entre otros: el control social, la convivencia social y política, la identidad y la acción cívico-comunitaria. De igual forma, desde la inclusión social, reconocida como la capacidad que tiene la sociedad de obtener una respuesta institucional a la compleja problemática de los barrios, se evidencia que los pobladores no creen en las instituciones de asistencia social y coercitiva, de hecho las cuestionan y deslegitiman.

Por último, la ética social engloba la consolidación de valores compartidos como la solidaridad, el respeto, la tolerancia y la reciprocidad. En el presente estudio, es posible observar que los pobladores expresan la falta de solidaridad entre pares, ya sea para la asistencia de un hecho violento o para la colaboración en asuntos vecinales.

De manera general, es posible observar que el nivel de cohesión social entre los habitantes de la comuna 11 es bajo, lo que permite deducir que esta condición influye en la capacidad que tienen los pobladores en asumir la violencia, reponerse de la misma y resistir a estas condiciones para construir hábitat, en otras palabras la vulnerabilidad. Al desaparecer la confianza y aparecer el miedo se supeditan las relaciones entre vecinos y se limitan a compartir un espacio, en donde prevalecen las conductas de evitación y se alimentan las tensiones y conflictividades

De esta manera, la cohesión social debe ser entendida como un concepto-contexto cíclico y sistémico, que reviste importancia en la medida que se le relaciona con la formación de 
identidad, pertenencia y solidaridad, condiciones importantes a la hora de consolidar las redes sociales. Según Kaztman y Retamoso (2005) citado por CIEPLAN $(2013,9)$ :

[...] en el caso de la situación de aislamiento social de los pobres [para citar un ejemplo], la concentración de hogares que enfrentan muchas carencias y la fragilidad del empleo, tienden a limitar la formación de redes de reciprocidad, y la creación y mantenimiento de instituciones barriales; todo lo cual va en detrimento del tejido social comunitario. La importancia de la trama social del vecindario, radica entonces, en ser la fuente de sociabilidad, formación de identidad y sentido de pertenencia más próxima a los espacios privados de la gente

Relación entre cohesión social y victimización

Para la determinación, la asociación o dependencia que tiene el hecho de haber sido víctima de un delito y el grado de cohesión social de los habitantes de la comuna 11, se usó una prueba de significación estadística haciendo uso de chi cuadrado $\left(X^{2}\right)$. Esta prueba determinó que existía dependencia estadística entre la cohesión social y la victimización, pues el valor de $X^{2}$ fue mayor que 5,9 (6,3) y el error típico menor que 0,05, situación que permite aceptar la hipótesis alternativa (relación entre las variables).

Lo anterior permite decir que existe una relación (estadísticamente significativa) entre el grado de cohesión social y la experiencia de victimización. Lo que implica relacionar a la violencia como un elemento que disminuye la cohesión social entre vecinos, otorgando desconfianza, miedo y disminuyendo los proyectos colectivos de construcción de hábitat, en otras palabras, esta relación denota en un factor de vulnerabilidad, donde el nivel de cohesión social es un indicador de las relaciones violentas en el barrio.

Al disminuir los elementos que integran, identifican y relacionan a los vecinos en un territorio, se pierden las redes por las que se establece el control social en las comunidades y se diluyen los canales comunitarios por los que se transmiten la solidaridad y el civismo, explicando (1) el porqué del bajo apoyo social que sienten las víctimas en los hechos violentos descritos en el capítulo 2 de la presente parte; (2) el control social pleno que ejercen las bandas criminales y (3) el bajo nivel de apropiación hacia el espacio público (en parte, porque la delincuencia también juega un papel fundamental). 


\section{A MANERA DE CONCLUSIÓN}

En síntesis, se observa que la cohesión social es un indicador del grado de confianza social que tienen los pobladores hacia sus vecinos y pares y hacia las instituciones legales. En el presente estudio se encontró que el nivel de cohesión social es bajo para toda la comuna y además que existe una relación estadística (de significancia) entre la experiencia de victimización y el nivel de este indicador.

Lo anterior permite entender la fragilidad de la población que se encuentra expuesta a la violencia, y por lo tanto su vulnerabilidad, ya que la cohesión social, como aglutinador social, es un mecanismo de defensa que tienen los pobladores ante los hechos que desestabilizan el orden legal socialmente establecido. Cuando este nivel de apropiación, relación y confianza, es bajo, entonces alta será la probabilidad de que se realicen prácticas violentas en el territorio, sin que se pueda recibir apoyo social o cuestionar los mecanismos de solución de conflictos, el establecimiento de las redes de poder y la obtención de recursos económicos de algunos actores.

De igual forma, el capital social, la integración social, la solidaridad los valores socioculturales y la percepción de seguridad en el barrio, se ven afectados por la violencia y la experiencia de victimización de los habitantes de esta comuna. Medir dicha relación puede ser un interesante ejercicio académico que puede dejar entrever el impacto que tiene la violencia como hecho social en la forma de relacionarse de los habitantes y en los patrones que generan identidad social entre los moradores de la comuna.

En este sentido, se afirma que una baja cohesión social vuelve más frágiles a los pobladores ante la violencia y permite que estos en la búsqueda de adaptarse a tal situación (violencia y falta de confianza) generen nuevos hábitos, nuevas formas de desplazarse y vivir dentro del barrio; construyan nuevas escalas de valores socio-culturales, en donde la ausencia de confianza y de apropiación son estrategias de prevención y seguridad; y recurran a la violencia como un mecanismo de reconocimiento, poder, calidad de vida y estatus.

\section{BIBLIOGRAFÍA}

ARBLASTER, A. "Violencia." Em Dicionário do pensamento social do século XX, por W OUTHWAITE e T BOTTOMORE, 803-805. Río de Janerio: Jorge Zahar Ed, 1996.

ARRIAGADA, Camilo, e SEPÚLVEDA, Daniela. Satisfacción residencial en vivienda básica SERVIU: la perspectiva del capital social. Serie VII, Política habitacional y planificación. Santiago de Chile: Ministerio de vivienda y urbanismo, República de Chile, 2002. 
ARTEAGA, Nelson. "El Espacio de la violencia: un modelo de interpretación social." Sociologica. año 18 No 52, 2003: 119-145.

BARBA SOLANO, Carlos. Em Perspectivas críticas sobre la cohesión social : Desigualdad y tentativas fallidas de integración social en América Latina, por CLACSO, edição: Carlos Barba Solano e Néstor Cohen, 67-86. Buenos Aires: CLACSO-CROP, 2011.

BELTRÁN, Isaac, e Velásquez, Elkin. “Cohesión social, confianza y seguridad en América Latina: Un estudio exploratorio." Em Violencia y cohesión social en América Latina, por Francisco Díaz e Patricio Meller, 49-104. Santiago de Chile: CIEPLAN, 2012.

BOURDIEU, Pierre. O poder simbólico. Río de Janeiro: Bertrand Brasil, 2001.

BRICEÑO-LEÓN, Roberto, AVILA, Olga, e CAMARDIEL, Alberto. Violencia e institucionalidad: informe del observatorio venezolano de violencia 2012. Caracas: Editorial Melvin, 2012.

CÁMARA DE COMERCIO DE BOGOTÁ. Encuesta de percepción y victimización. 15 años de aplicación, Bogotá $y$ sus localidades, segundo semestre de 2012.2013. http://www.ccb.org.co/contenido/contenido.aspx?catID=126\&conID=562. Recuperado el 15 de Marzo de 2013.

CEPAL. Cohesión social. Inclusión y sentido de pertenencia en América Latina y el Caribe. Santiago de Chile: Naciones Unidas, 2007.

CHAUÍ, Marilena. "Uma ideologia perversa: explicacoes para a violencia impedem que a violencia real se torne compreensível." Folha de Sao Paulo, 1999: 3-5.

CIEPLAN. Cuadernos de Barrio No 2. Encuesta de cohesión social: Una mirada de los consejos vecinales de desarrollo de la Región Metropolitana. Santiago de Chile: Universidad Diego Portales, 2013.

CIEPLAN et al. Encuesta de cohesión social en América Latina. Santiago de Chile: CIEPLAN, 2007.

DAMMERT, Lucía. "Inseguridad, crimen y cohesión social en América Latina: ¿Es posible pasar del discurso a la evidencia?" Em Violencia y cohesión social en América Latina, por Francisco Díaz e Patricio (eds.) Meller, 27-48. Santiago de Chile: CIEPLAN, 2012.

DAMMERT, Lucía, e ARIAS, Patricia. "El desafío de la delincuencia en América Latina: diagnóstico y respuesta de política-." Em Seguridad y Violencia: desafíos para la ciudadanía, por Lucía Dammert e Lisa (eds.) Zuñiga, 21-66. Santiago de Chile: FLACSO, 2007.

DANE. Departmento Administrativo Nacional de Estadística. Colombia, estimaciones de la migración. 1985-2005 y proyecciones 2050-2020. Nacionales y Departamentales. 2015. http://www.dane.gov.co/index.php/poblacion-y-demografia/movilidad-y-migracion (acesso em 8 de Feb de 2015).

Encuesta de Convivencia y Seguridad Ciudadana. 2012b. http://www.dane.gov.co/files/investigaciones/poblacion/convivencia/Pres_ecsc.pdf. Recuperado el 2 de Noviembre de 2012. 
"Encuesta

de

victimización."

$2012 e$.

http://www.dane.gov.co/index.php?option=com_content\&view=article\&id=110\&ltemid=80.

Recuperado el 23 de Noviembre de 2012.

DÍAZ, Francisco, e MELLER, Patricio. "Violencia y cohesión social en América Latina: Perspectiva histórica." Em Violencia y cohesión social en América Latina, por Francisco Díaz e Patricio (eds.) Meller, 11-26. Santiago de Chile: CIEPLAN, 2012.

MUNICIPIO DE DOSQUEBRADAS. Comunas y Barrios. 2012. http://www.dosquebradas.gov.co/index.php?option=com_content\&view=article\&id=2985\%3Acom unasbarrios\&catid=30\%3Aterritorios\&Itemid=40\&lang=es. Recuperado el 10 de Octubre.

DURKHEIM, Emilie. La división del trabajo social. Madrid: Akal, 1987.

EUROSOCIAL. Cohesión social. 2013. http://www.eurosocial-ii.eu/eurosocial/quehacemos/cohesion-social. Recuperado el 2 de Febrero de 2013.

GALTUNG, Johan. Investigaciones teóricas: Sociedad y cultura contemporáneas. Madrid: Tecnos, 1995.

INSTITUTO NACIONAL DE MEDICINA LEGAL Y CIENCIAS FORENSES. "Forensis." Datos oficiales sobre $\begin{array}{lll}\text { la } & \text { violencia. } & 2015 .\end{array}$

http://www.medicinalegal.gov.co/forensis;jsessionid=96ED6B61158BA9A55285BAF0598C91A9 (acesso em 1 de Febrero de 2015).

JIMÉNEZ, Williams. "Hacía una tipología de lugares peligrosos. Caso de estudio de la comuna 11 de Dosquebradas, Colombia." Revista Criminalidad 56, no 1 (2014): 133-156.

KAZTMAN, Rúben, e RETAMOSO, Alejandro. "Segregación espacial, empleo y pobreza en Montevideo." Em Cuadernos de Barrio No 2. Encuesta de cohesión social: Una mirada de los consejos vecinales de desarrollo de la Región Metropolitana, por CIEPLAN, 131-148. Santiago de Chile: Universidad Diego Portales, 2005.

KEANE, John. Reflexiones sobre la violencia. España: Alianza Editorial, 2000.

MARCHIORI, Hilda. Estudios sobre victimización. Córdoba: Encuentro grupo editor, 2006.

MARTUCELLI, Danilo. Dominations ordinaires. Explorations de la condition moderne. Paris: Balland, 2001.

ORGANIZACIÓN MUNDIAL DE LA SALUD. World health report on violence and health. 2002. http://www.paho.org/Spanish/AM/PUB/capitulo_1.pdf. Recuperado el 8 de Junio de 2012.

SERRANO, Claudia, e MODREGO, Félix. "Cohesión territorial: La dimensión ausente del desarrollo en América Latina." Em Violencia y cohesión social en América Latina, por Francisco Díaz e Patricio Meller, 235-278. Santiago de Chile: CIEPLAN, 2012. 
UNITED NATIONS. United Nations office on drugs and crime. Manual on victimization surveys. Geneva: United Nations, 2010.

VARELA, HIlda. "Introducción: la violencia política y la condición humana." Em Violencia: Estado y sociedad, una perspectiva histórica, por Marta Ortega, José Castañeda e Francisco Lazarín. Ciudad de México: Miguel Angel Porrúa y la Universidad Autonoma Metropolitana, 2004.

VELÁSQUEZ, Elkin. Gobernanza de la seguridad pública. Bogotá: Instituto Latinoaméricano de Altos Estudios Sociales, 2008.

Trabalho enviado em 30 de janeiro de 2016.

Aceito em 08 de março de 2016. 